\title{
ptsI gene in the phosphotransfer system is a potential target for developing a live attenuated Salmonella vaccine
}

\author{
YONG ZHI ${ }^{1,2}$, SHUN MEI LIN ${ }^{1}$, KI BUM AHN ${ }^{1}$, HYUN JUNG JI ${ }^{1}$, HUI-CHEN GUO ${ }^{3}$, \\ SANGRYEOL RYU ${ }^{4}$, HO SEONG SEO ${ }^{1,2}$ and SANGYONG LIM ${ }^{1,2}$
}

\author{
${ }^{1}$ Radiation Science Division, Korea Atomic Energy Research Institute, Jeongeup, Jeollabookdo 56212; \\ ${ }^{2}$ Department of Radiation Science, University of Science and Technology, Daejeon 34113, Republic of Korea; \\ ${ }^{3}$ State Key Laboratory of Veterinary Etiological Biology, National Foot and Mouth Disease Reference Laboratory, \\ Lanzhou Veterinary Research Institute, Chinese Academy of Agricultural Sciences, Lanzhou, Gansu 730049, P.R. China; \\ ${ }^{4}$ Department of Food and Animal Biotechnology, Seoul National University, Seoul 08826, Republic of Korea
}

Received August 29, 2019; Accepted January 7, 2020

DOI: $10.3892 /$ ijmm.2020.4505

\begin{abstract}
Salmonella enterica serovar Typhimurium causes invasive non-typhoidal Salmonella diseases in animals and humans, resulting in a high mortality rate and huge economic losses globally. As the prevalence of antibiotic-resistant Salmonella has been increasing, vaccination is thought to be the most effective and economical strategy to manage salmonellosis. The present study aimed to investigate whether dysfunction in the phosphoenolpyruvate:carbohydrate phosphotransferase system (PTS), which is critical for carbon uptake and survival in macrophages, may be adequate to generate Salmonella-attenuated vaccine strains. A Salmonella strain (KST0555) was generated by deleting the ptsI gene from the PTS and it was revealed that this auxotrophic mutant was unable to efficiently utilize predominant carbon sources during infection (glucose and glycerol), reduced its invasion and replication capacity in macrophages, and significantly $(\mathrm{P}=0.0065)$ lowered its virulence in the setting of a mouse colitis model, along with a substantially decreased intestinal colonization and invasiveness compared with its parent strain. The reverse transcription-quantitative PCR results demonstrated that the virulence genes in Salmonella pathogenicity island-1 (SPI-1) and -2 (SPI-2) and the motility of KST0555 were all downregulated compared with its parent strain. Finally, it was revealed that when mice were immunized orally with live
\end{abstract}

Correspondence to: Dr Sangyong Lim or Dr Ho Seong Seo, Radiation Science Division, Korea Atomic Energy Research Institute, 137 Main Building, 29 Geumgu-gil, Jeongeup, Jeollabookdo 56212, Republic of Korea

E-mail: saylim@kaeri.re.kr

E-mail: hoseongseo@kaeri.re.kr

Key words: Salmonella enterica serovar Typhimurium, phosphotransferase system, mouse colitis model, auxotrophic bacterial vaccine, humoral immunity, cellular immunity
KST0555, Salmonella-specific humoral and cellular immune responses were effectively elicited, providing protection against Salmonella infection. Thus, the present promising data provides a strong rationale for the advancement of KST0555 as a live Salmonella vaccine candidate and $p t s I$ as a potential target for developing a live attenuated bacterial vaccine strain.

\section{Introduction}

Non-typhoidal Salmonella (NTS) is a leading cause of bacterial bloodstream infections in infants, the elderly and immunocompromised people, particularly in sub-Saharan Africa, where the case fatality rate is $20-25 \%(1,2)$. In sub-Saharan Africa, invasive NTS (iNTS) has been reported to be the second most common invasive bacterial disease type (29\%), followed by Streptococcus pneumoniae infection $(3,4)$. S. enterica serovar Typhimurium is the most common iNTS isolate, followed by S.enterica serovar Enteritidis $(3,4)$. Although Salmonella may be controlled using antibiotics, an increasing prevalence of multidrug-resistant strains has been reported over previous decades $(5,6)$. Thus, vaccine development is a potential prospect for controlling the epidemic prevalence of iNTS in humans in addition to animals (7). At present, two types of licensed Salmonella vaccines for typhoid fever are considered safe and efficacious for people aged over 2 years (8); however, there is no vaccine directly targeting iNTS. Vivotif ${ }^{\circledR}$, a live oral vaccine containing a mutated Salmonella (Ty21a), may effectively elicit intestinal antibodies against $\mathrm{O}$-antigens, which likely exhibits cross-protective efficacy against NTS, including $S$. Typhimurium and $S$. Enteritidis (9-11).

With the limitations of these existing vaccines, numerous subunit and live-attenuated vaccines for iNTS diseases are being developed, and a number of them are undergoing clinical studies $(12,13)$. Approaches to subunit vaccines mainly focus on the application of the $\mathrm{O}$-antigens of lipopolysaccharides and surface virulence factors, including flagellin and outer membrane proteins (14-16). These subunit vaccines potentially have the advantage of cross-protection, safety and low production cost (17). However, numerous subunit vaccines against 
bacterial pathogens have not been successful as the conformational changes in conserved epitopes during preparation result in poor humoral and long-lasting immunity, and a single structurally conserved protein, even if it is a critical virulence factor, would not be sufficient to provide effective immunity $(18,19)$. Previously, numerous novel strategies for developing live NTS vaccines have been introduced. Most of the live attenuated Salmonella vaccine strains have been constructed by deleting functional metabolic gene(s) and/or virulence gene(s) (20-23). Among the candidate vaccine strains for iNTS, only a few were tested in clinical studies. LH1160, a phoPQ mutant strain that controls the transcription of multiple genes necessary for intracellular survival, had been tested in phase 1 clinical trials, but an unacceptable fever was reported in two of six volunteers immunized with LH1160 $(21,24)$. WT05 is another attenuated $S$. Typhimurium vaccine in which the $\operatorname{aroC}$ gene, involved in aromatic amino acid biosynthesis, and the ssaV gene, a component of a Type 3 secretion system (T3SS) apparatus of Salmonella pathogenicity island 2 (SPI-2), are deleted. However, this vaccine also failed in phase 1 clinical trial due to the prolonged stool shedding of the vaccine strain in healthy volunteers immunized with WT05 $(25,26)$. More recently, CVD1921, which is mutated in the guaBA genes that are involved in the biosynthesis of guanine nucleotides and the $\operatorname{clp} P$ gene affecting flagella expression, was revealed to be notably attenuated with decreased shedding, systemic spread and clinical disease manifestations in the digestive tract of the non-human primate model (rhesus macaque) used (27).

When Salmonella are internalized into the intracellular compartment of host cells, they need to adapt to the metabolism of available nutrients, mainly the carbon source in host cells $(28,29)$. Multiple carbon transport systems are known to be involved in the intracellular life cycle and linked to the virulence of Salmonella (30-32). For example, the carbohydrate phosphotransferase system (PTS) is composed of two cytoplasmic proteins, enzyme I ( $p t s I)$ and histidine protein $(p t s H)$, which are common to all PTS sugars, and membrane-bound enzyme II (EII) complex (crr), which is critical for sugar uptake (33). In a previous study, the removal of two components genes, ptsI and crr, in PTS was reported, and was revealed to be adequate to construct Salmonella-attenuated vaccine strains to provide protective humoral and mucosal immune responses, but a less effective cell-mediated immune response (34).

In the present study, a new attenuated Salmonella strain vaccine was developed by deleting the ptsI (EI) gene in the carbohydrate phosphotransferase ( $p t s H, p t s I$ and $c r r$ ) operon. Furthermore, the humoral, cellular and protective effects of the vaccine were evaluated in a mouse model.

\section{Methods and materials}

Ethics statement. The present study was performed in strict accordance with the recommendations in the Guide for the Care and Use of Laboratory Animals of the National Institutes of Health. All animal experiments were ethically approved by the Committee on The Use and Care of Animals at the Korea Atomic Energy Research Institute (KAERI; approval nos. IACUC-2016-028, IACUC-2017-010 and IACUC-2018-007) and performed according to accepted veterinary standards set by the KAERI animal care center. An overall weight-loss of $25 \%$ was considered to be an indication for euthanasia. All efforts were made to minimize the suffering of the animals employed in the present study. To euthanize the mice, a $\mathrm{CO}_{2}$ inhalation method as specified by KAERI Institutional Animal Care and Use Committee guidelines was used. Less than five mice were placed in a visible cage chamber (L27xW21xH17) and injected with compressed grade $\mathrm{B} \mathrm{CO}_{2}$ gas in cylinders. A fill rate of $10-30 \%$ of the cage chamber volume per minute with $\mathrm{CO}_{2}$, which was 1-3 liter(s) per min, was appropriate to achieve a balanced gas mixture to fulfill the objective of rapid unconsciousness with minimal distress to the animals. Expected time to unconsciousness was usually reached at within 1-3 min and the flow was maintained for additional $1 \mathrm{~min}$ once respiration had ceased. If both signs were observed, then the mice were removed from the cage.

Reagents. All chemical reagents used in the present study were purchased from Sigma-Aldrich (Merck KGaA).

Bacterial strains and growth conditions. All bacteria strains used in the present study are listed in Table I. Salmonella strains were grown at $37^{\circ} \mathrm{C}$ in Luria-Bertani (LB) broth (Difco; BD Biosciences), M9 minimum media (Sigma-Aldrich; Merck $\mathrm{KGaA}$ ) or phagosome-mimicking MES-buffered medium [5 mM KCl, $7.5 \mathrm{mM}(\mathrm{NH} 4)_{2} \mathrm{SO}_{4}, 0.5 \mathrm{mM} \mathrm{K}_{2} \mathrm{SO}_{4}, 1 \mathrm{mM}$ $\mathrm{KH}_{2} \mathrm{PO}_{4}, 8 \mathrm{mM} \mathrm{MgCl}, 0.1 \%$ casamino acids, $0.4 \%$ carbon source and $170 \mathrm{mM} 2-(N$-morpholino) ethanesulphonic acid, $\mathrm{pH}=5.6]$ (35). The media were supplemented with kanamycin $(50 \mu \mathrm{g} / \mathrm{ml})$, chloramphenicol $(15 \mu \mathrm{g} / \mathrm{ml})$ or ampicillin $(100 \mu \mathrm{g} / \mathrm{ml})$, if required.

Salmonella mutants construction. S. Typhimurium strains used in the present study were derived from wild type (WT) strain UK1 (KST0134) (36). The ptsI-deficient strain (KST0555) was constructed using $\lambda$ red-recombinase-mediated replacement as described previously (37). In brief, a kanamycin resistance $\left(\mathrm{Km}^{\mathrm{R}}\right)$ cassette was amplified from the pKD13 plasmid that was annealed to the flanking regions of the deletion-target sites by using the primers listed in Table II. The resulting PCR product was transferred to UK1 harboring the plasmid pKD46 by electrophoresis, and the mutant was isolated on a kanamycin plate. The generated mutant was transformed with pCP20 to excise the $\mathrm{Km}^{\mathrm{R}}$ cassette. Salmonella strains containing HA or 3xFLAG epitope tag in HilA and HilD and transcriptional lac fusion with sseA promoter (sseA::lacZY) were constructed using P22 transduction as described previously $(38,39)$.

$\beta$-galactosidase assay. A $\beta$-galactosidase assay was performed as described previously (40). Overnight cultures of Salmonella KST0134 (WT), KST0555 (DptsI) and KST0650 ( $\Delta$ hilD) were sub-cultured into fresh LB broth or MES-buffered minimum media. Salmonella bacteria were harvested at 2, 4, 6, 8, 10 and $12 \mathrm{~h}$ post-inoculation, followed by resuspension with $1 \mathrm{ml} \mathrm{Z}$-buffer $\left(0.06 \mathrm{M} \mathrm{Na}_{2} \mathrm{HPO}_{4}, 7 \mathrm{H}_{2} \mathrm{O}\right.$, $0.04 \mathrm{M} \mathrm{NaH}_{2} \mathrm{PO}_{4}, \mathrm{H}_{2} \mathrm{O}, 0.01 \mathrm{M} \mathrm{KCl}, 0.01 \mathrm{M} \mathrm{MgSO}_{4}, 7 \mathrm{H}_{2} \mathrm{O}$ and $0.05 \mathrm{M} \beta$-mercaptoethanol; $\mathrm{pH}=7.0$ ), and permeabilized with $20 \mu \mathrm{l} 0.1 \%$ sodium dodecylsulfate and $40 \mu \mathrm{l}$ chloroform. Following $10 \mathrm{~min}$ of incubation at room temperature, $200 \mu \mathrm{l}$ O-nitrophenyl $\beta$-glactopyranoside (ONPG; $4 \mathrm{mg} / \mathrm{ml}$ ) was 
Table I. Strains and plasmids used in the present study.

A, Escherichia coli

\begin{tabular}{|c|c|c|c|c|}
\hline Author, year & Strain & Relevant gene & Source & (Refs.) \\
\hline na & DH5 $\alpha$ & $\mathrm{F}^{-} \mathrm{rm}^{+} \emptyset 80 \mathrm{~d} l a c \mathrm{Z} \Delta \mathrm{M} 15$ & Gibco; Thermo Fisher Scientific, Inc. & na \\
\hline
\end{tabular}

B, Salmonella Typhimurium

\begin{tabular}{|c|c|c|c|c|}
\hline Author, year & Strain & Relevant gene & Source & (Refs.) \\
\hline na & UK1 & Clinical isolate from horse ATCC68169 & American Type Culture Collection & na \\
\hline \multirow[t]{2}{*}{ Abed et al, 2014} & BH129 & UK1, $\operatorname{sptsI(Tn:10)}$ & na & (1) \\
\hline & KST0555 & $\mathrm{UK} 1, \Delta p t s I$ & The present study & \\
\hline \multirow[t]{5}{*}{ Abed et al, 2014} & KST0650 & UK1, shilD & na & (1) \\
\hline & KST0600 & UK1 hilA::HA-Kana ${ }^{\mathrm{R}}$ & The present study & \\
\hline & KST0601 & KST0555 hilA::HA-Kana ${ }^{R}$ & The present study & \\
\hline & KST0597 & UK1 hilD::HA-Kana ${ }^{\mathrm{R}}$ & The present study & \\
\hline & KST0598 & KST0555 hilD::HA-Kana ${ }^{\mathrm{R}}$ & The present study & \\
\hline \multirow[t]{4}{*}{ Febriani et al, 2010} & KST0134 & SL1344, sseA::lacZY-Kana ${ }^{\mathrm{R}}$ & na & (2) \\
\hline & KST0589 & UK1, sseA::LacZY-Kana ${ }^{\mathrm{R}}$ & The present study & \\
\hline & KST0590 & KST0555, sseA::LacZY-Kana ${ }^{\mathrm{R}}$ & The present study & \\
\hline & KST0583 & UK1, shilD, sseA::LacZY-Kana ${ }^{\mathrm{R}}$ & The present study & \\
\hline
\end{tabular}

C, Plasmid

\begin{tabular}{|c|c|c|c|c|}
\hline Author, year & Strain & Relevant gene & Source & (Refs.) \\
\hline Ao et al, 2015 & pKD46 & $\mathrm{P}_{\mathrm{BAD}}$-gam-beta-exo oriR101 repA101 ${ }^{L S} ; \mathrm{Amp}^{\mathrm{R}}$ & na & (3) \\
\hline Ao et al, 2015 & pKD13 & FRT Kana ${ }^{\mathrm{R}}$ FRT PS1 PS4 oriR6K; Amp $^{\mathrm{R}}$ & na & (3) \\
\hline Ao et al, 2015 & pCP20 & $c \mathrm{I} 857 \mathrm{P}_{\mathrm{R}}$ flp oripSC101 ${ }^{\mathrm{ts}} ; \mathrm{Amp}^{\mathrm{R}} \mathrm{Cm}^{\mathrm{R}}$ & na & (3) \\
\hline
\end{tabular}

na, not applicable; Kana, kanamycin; Cm, chloramphenicol; Amp, ampicillin.

added as the substrate, and the mixture was incubated at $30^{\circ} \mathrm{C}$ for $30 \mathrm{~min}$ in a water bath until the sample turned bright yellow. The reaction was stopped by adding $1 \mathrm{M} \mathrm{Na}_{2} \mathrm{CO}_{3}$ $(500 \mu \mathrm{l})$, and the incubation period, i.e., the time between the addition of the ONPG substrate and the addition of stop solution, was recorded. The optical density ${ }_{420}$ was recorded, and the specific activity and protein concentration were determined. The $\beta$-galactosidase activity was expressed in Miller units as described previously (40). Miller units were calculated as follows:

$$
1,000 \times \frac{(\text { Abs } 420)-1.75 * \text { Abs550 }}{(\text { Abs600 of culture sample }) *(\text { volume of culture }) *(\text { reaction time })}
$$

Cell invasion and replication assays. Experimental procedures were performed as described previously (30). The mouse macrophage cell lines (RAW264.7; cat. no. ATCC ${ }^{\circledR}$ TIB-71) and rat small intestinal epithelial cells (IEC-6; cat. no. ATCC ${ }^{\circledR}$ CRL-1592 ${ }^{\mathrm{TM}}$ ) were purchased from the Korean Cell Line Bank. Cells were cultured in DMEM (Gibco; Thermo Fisher Scientific, Inc.) supplemented with $10 \%$ fetal bovine serum (Gibco; Thermo Fisher Scientific, Inc.), $100 \mathrm{U} / \mathrm{ml}$ penicillin and $100 \mu \mathrm{g} / \mathrm{ml}$ streptomycin at $37^{\circ} \mathrm{C}$ and $5 \% \mathrm{CO}_{2}$. The cells were plated in 48-well cell culture plates (SPL Life Sciences) at IEC-6 ( $1 \times 10^{5}$ cells) and RAW264.7 (5x10 cells) per well and incubated for $2 \mathrm{~h}$ at $37^{\circ} \mathrm{C}$. Overnight-cultured Salmonella were washed with phosphate buffered saline (PBS) and suspended with DMEM, followed by addition to the prepared cell monolayers at multiplicity of infection (MOI) of 10. Following $1 \mathrm{~h}$, the cells were washed three times with PBS, followed by an addition of pre-warmed medium containing $100 \mu \mathrm{g} / \mathrm{ml}$ gentamicin to remove extracellular bacteria. At 2 and $18 \mathrm{~h}$ post-infection (hpi), the wells were washed with PBS three times and lysed with $0.5 \%$ Triton-X100. Finally, the cell lysate was serially diluted with PBS, and $10 \mu \mathrm{l}$ of the diluents was spotted on LB/agar plates to determine the number of colony forming units (CFUs). CFUs in the range of 20 to 50 colonies per spot from each dilution were counted. All data were calculated from at least three independent experiments performed in triplicate.

Fluorescence microscopic analysis. Infected Salmonella cells were visualized by plating RAW264.7 cells on $15 \mu \mathrm{m}$ Chamber 
Table II. Primers used in the present study.

\begin{tabular}{|c|c|c|}
\hline Gene & Forward primer sequence $\left(5^{\prime}-3^{\prime}\right)$ & Reverse primer sequence $\left(5^{\prime}-3\right.$ ') \\
\hline hilA & ATTAAGGCGACAGAGCTGGA & ATAGCAAACTCCCGACGATG \\
\hline$i n v F$ & TGTCGCACCAGTATCAGGAG & AAATAGCGCGAAACTCAGGA \\
\hline$s s a G$ & GATATGCTCTCCCACATGGC & AGGCAAATTGCGCTTTAATC \\
\hline$s s a B$ & GGATTCATGCTGGCAGTTTT & GCAGGATGCCCATCAATAGT \\
\hline $\operatorname{sse} A$ & AGGAGGCCGAGAAGGATTTA & TTCCTGACGGTATCTCCACC \\
\hline$s s r A$ & CATGTTTGTGGCACTATCCG & GCGAGCTAAGGTAGCCAATG \\
\hline $\operatorname{sip} A$ & AAACGTTGATACCCCTGCTG & GACATGGCTTCGGCTATTGT \\
\hline $\operatorname{sip} B$ & TGTTTCGCTGTCTCAACTGG & TCGCAGCGTCATAAACACTC \\
\hline $\operatorname{sip} C$ & AAGTCAGTGACCTGGGGTTG & AACGGCACTGGAAGACATTC \\
\hline $\operatorname{sip} D$ & ACTGCCGTGGTACCGTCTAC & ATAATGACACGCCGGACTTC \\
\hline fth $D$ & CAACGAAGAGATGGCAAACA & GACGCGTTGAAAGCATGATA \\
\hline fliA & CCGCTGAAGGTGTAATGGAT & CCGCATTTAATAACCCGATG \\
\hline$f i z$ & AAACATTTCCCACGATCTGC & CGGTAAAGGGGGATTTCTGT \\
\hline flgM & CCTTTGAAACCCGTTAGCAC & GCCGTTTTTAATGCTTCGAC \\
\hline $\mathrm{fliC}$ & AACGACGGTATCTCCATTGC & TACACGGTCGATTTCGTTCA \\
\hline pts Imutant & AAGTTTTTTTTCCGGGTTCTTTTAAAAATCA & GCAGTTCCTGTTTGTAGATTTCTTTGCGCAG \\
\hline Construction & $\begin{array}{l}\text { GTCACAAGTAAGGTAGGGTTCATATGAATAT } \\
\text { ССТССТTA }\end{array}$ & $\begin{array}{l}\text { CGCGCGAACTTCTTGTCAATCTAGGCTGGA } \\
\text { GCTGCTTC }\end{array}$ \\
\hline
\end{tabular}

12-well glass slides (Ibidi $\mathrm{GmbH}$ ), followed by infection with WT and KST0555 strains at a MOI of 10 at $37^{\circ} \mathrm{C}$ for $1 \mathrm{~h}$. DMEM containing gentamicin $(100 \mu \mathrm{g} / \mathrm{ml})$ was used to eliminate extracellular bacteria. Following 2 or $18 \mathrm{~h}$ of infection, the cells were fixed with $4 \%$ paraformaldehyde for $30 \mathrm{~min}$ at $4^{\circ} \mathrm{C}$ and permeabilized with $0.1 \%$ Triton-X100 in PBS for $20 \mathrm{~min}$. The cells were then washed three times with PBS and blocked with $3 \%$ bovine serum albumin (BSA; Sigma-Aldrich; Merck KGaA) in PBS for up to $2 \mathrm{~h}$ at room temperature. Intracellular Salmonella were detected by incubating the cells with fluorescein isothiocyanate (FITC)-conjugated anti-rabbit Salmonella-specific antibodies (cat. no. ab20320; 1:1,000; Abcam) at room temperature for $30 \mathrm{~min}$. The nuclei were stained with $150 \mathrm{ng} / \mathrm{ml}$ 4',6-diamino-2-phenylindole for $5 \mathrm{~min}$ at $37^{\circ} \mathrm{C}$ (Thermo Fisher Scientific, Inc.). All images were captured using an Olympus CX41 fluorescence microscope (Olympus Corporation).

Mice experiments. Animal housing conditions (specific pathogen-free) and the animal experimental design were ethically approved by the Committee on The Use and Care of Animals at the KAERI and performed according to accepted National Health Institute standards. A total of 90 six-week-old male BALB/c mice (weight, 19-21 g) were purchased from OrientBio Inc. Five mice were randomly assigned per individually ventilated housing cage (OrientBio Inc.) maintained in an animal biological safety level 2 facility at $22-23^{\circ} \mathrm{C}$ on a 12 h:12 h light:dark cycle. Cages were covered with high efficiency particulate air-filtered microisolation lids (OrientBio Inc.) in a static airflow environment. Bedding (Aspen Shaving; OrientBio Inc.) at an approximate depth of $1.0 \mathrm{~cm}$ was changed weekly. Irradiated rodent diet food and sterile water were provided ad libitum, supported by the wire cage top. Conscious mice were weighed (PB602-S balance; Mettler Electronics Corp.) at regular intervals using the $10 \mathrm{sec}$ dynamic weighing method. For measuring the virulence of Salmonella in the settings of a mice colitis model, mice $(n=5)$ were administered $20 \mathrm{mg}$ streptomycin (Sigma-Aldrich; Merck KGaA) in sterile water. Water and food were withdrawn for $4 \mathrm{~h}$ prior to streptomycin administration. Subsequently, the animals were supplied with water and food. At $20 \mathrm{~h}$ following streptomycin treatment, water and food were withdrawn again for $4 \mathrm{~h}$ prior to the administration of Salmonella orally (41). At the time of mortality or $72 \mathrm{~h}$ post-infection (hpi), mouse spleens, mesenteric lymph nodes and ceca were aseptically isolated, and the number of viable bacteria in each organ were determined by plating serially diluted homogenates or blood on LB agar plates. For further verifying the protection capacity of the KST0555 vaccination, five mice were immunized orally with $10^{7} \mathrm{CFU}$ KST0555 in $100 \mu$ l PBS three times at two-week intervals. At 7 days following the last immunization, $10^{7} \mathrm{CFU}$ WT were inoculated orally, and mortality and body weight changes were observed and recorded for 2 weeks. In all experiments, mice were considered to have succumbed to mortality and euthanized when they reached $75 \%$ of their original bodyweight.

Reverse transcription-quantitative PCR (RT-qPCR) analysis. Log-phase cultures of WT (KST0134) and KST0555 were diluted 100-fold into fresh LB broth or MES-buffered minimum media $(\mathrm{pH}=5.6)$, followed by incubation for $4 \mathrm{~h}$ at $37^{\circ} \mathrm{C}$ overnight with shaking (42). Total RNA was isolated from bacterial cultures by using an RNeasy ${ }^{\circledR}$ mini kit (Qiagen $\mathrm{GmbH}$ ) according to manufacturer's protocol. For RT-qPCR analysis, cDNA was synthesized from $1 \mu \mathrm{g}$ total purified RNA using a Primescript 1st strand cDNA synthesis kit (Takara Bio, Inc.) according to manufacturer's protocol. Primers for different genes were designed based on Primer Express software (version 2.0; Applied Biosystems, Thermo Fisher Scientific, Inc.) and are listed in Table II. RT-qPCR amplification was 
performed using SYBR Premix EX Taq (Takara Bio, Inc.) on a Bio-Rad CFX Real-Time System (Bio-Rad Laboratories, Inc.). Thermocycling conditions were as follows: One cycle at $95^{\circ} \mathrm{C}$ for $10 \mathrm{~min}$, followed by 40 cycles at $95^{\circ} \mathrm{C}$ for $15 \mathrm{sec}, 60^{\circ} \mathrm{C}$ for $30 \mathrm{sec}, 72^{\circ} \mathrm{C}$ for $30 \mathrm{sec}$, and a final extension at $72^{\circ} \mathrm{C}$ for $10 \mathrm{~min}$. The relative gene expression was quantified using the $2^{-\Delta \Delta \mathrm{Cq}}$ method (43). The $16 \mathrm{~S}$ rRNA $(r r s H)$ was selected as a control to normalize the expression levels.

Agar plate motility assay. A motility assay was performed as described previously (44). Briefly, $5 \mu$ l overnight cultures grown in LB broth were spotted onto the surface of a swarm plate (LB; $0.5 \%$ Bacto agar and $0.5 \%$ glucose) and incubated at $37^{\circ} \mathrm{C}$ for $24 \mathrm{~h}$.

Western blot analysis. Whole Salmonella lysates $\left(10^{8} \mathrm{CFU}\right)$ were lysed in buffer (1\% v/v Triton X-100 and 0.1\% w/v SDS in PBS) and loaded and separated on $12 \%$ Bis-Tris BOLT gels (Invitrogen; Thermo Fisher Scientific, Inc.), followed by transfer onto nitrocellulose membranes. The membranes were blocked with $5 \%$ dry skimmed milk (Bio-Rad Laboratories, Inc.) in PBS with $0.05 \%$ Tween-20 (PBS-T) for $30 \mathrm{~min}$ at room temperature and then incubated with monoclonal anti-FLAG antibody (1:3,000; cat. no. F2555; Sigma-Aldrich; Merck KGaA), monoclonal anti-HA antibody (1:4,000; cat. no. ab137838; Abcam) or rabbit polyclonal anti-DnaK (1:3,000; cat. no. ab80161; Abcam). Following primary antibody incubation, the membranes were incubated with an anti-mouse total immunoglobulin (Ig) or anti-rabbit IgG conjugated with horseradish peroxidase-conjugated secondary antibody (1:5,000; cat. no. A9044; Sigma-Aldrich; Merck KGaA; Merck KGaA) for $1 \mathrm{~h}$ at room temperature. The protein bands were visualized using Enhanced Chemiluminescent Western Blotting Substrate (Thermo Fisher Scientific, Inc.). Bio-Rad ChemiDoc $^{\text {TM }}$ Touch imaging system and Bio-Rad CFX Manager software (version 3.1; Bio-Rad Laboratories, Inc.) were used for data acquisition and analysis.

Measurement of mice immunoglobulin. Mice blood samples were obtained 7 days subsequent to the last immunization. The serum was isolated by centrifugation at $500 \mathrm{x}$ g for $10 \mathrm{~min}$ at $4^{\circ} \mathrm{C}$ and stored at $-80^{\circ} \mathrm{C}$ for long-term use. Salmonella were cultured in LB and harvested at mid-log phase. The absorbance of the Salmonella pellet was adjusted to 0.1 at $600 \mathrm{~nm}$ by dilution with PBS. Next, 96-well immunoplates (SPL Life Sciences) were coated with $100 \mu 1$ Salmonella or $1 \mu \mathrm{g}$ Salmonella lipopolysaccharide (LPS; Sigma-Aldrich; Merck $\mathrm{KGaA}$ ) and incubated overnight at $4^{\circ} \mathrm{C}$ to allow the immobilization of bacterial cells onto the wells. The plates were washed five times with PBS-T, followed by blocking with $1 \%$ BSA in PBS for $1 \mathrm{~h}$ at room temperature. Subsequent to blocking, diluted sera were added to each well and incubated at room temperature for $1 \mathrm{~h}$, followed by the washing of unbound antibodies with PBS-T. Secondary antibodies (all 1:4,000) were added to the wells by and incubated for $30 \mathrm{~min}$ at room temperature. The secondary antibodies were as follows: Goat anti-mouse Ig-HRP (cat. no. A0412; Sigma-Aldrich, Merck KGaA), goat anti-mouse IgG-HRP (cat. no. 1030-05; SouthernBiotech), goat anti-mouse IgM-HRP (cat. no. 1020-05; SouthernBiotech), goat anti-mouse IgG1-HRP (cat. no. 1071-05; SouthernBiotech), goat anti-mouse IgG2a-HRP (cat. no. 1080-05; SouthernBiotech), goat anti-mouse IgG2b-HRP (cat. no. 1090-05; SouthernBiotech) and goat anti-mouse IgG3-HRP (cat. no. 1100-05; SouthernBiotech). The plates were then washed 5 times with PBS-T, and $100 \mu \mathrm{l}$ of 3,3',5,5'-tetramethylbenzidine substrate reagent (BD Biosciences) was added. When the color developed, $50 \mu \mathrm{l}$ $2 \mathrm{~N} \mathrm{H}_{2} \mathrm{SO}_{4}$ was added, and the absorbance was measured at $450 \mathrm{~nm}$ by using a Victor X3 light plate reader (PerkinElmer, Inc.). The assigned titer value was indicative of the last dilution in which $\mathrm{A}_{450}$ is $<0.1$.

Cytokine measurement. Splenocytes $\left(1 \times 10^{5}\right.$ cells/well) were plated onto a round bottom 96-well plates (SPL Life Sciences) and incubated with PBS or $S$. Typhimurium WT lysate prepared by sonication for $72 \mathrm{~h}$ at $37^{\circ} \mathrm{C}$. Interleukin- 4 (IL-4) and interferon- $\gamma$ (IFN- $\gamma$ ) levels in the supernatants were measured using mouse IL-4 (cat. no. 555232; BD Biosciences) and mouse IFN- $\gamma$ (cat. no. 555138; BD Biosciences) ELISA kits, respectively.

Adoptive transfer of sera, $C D 4^{+}$and $C D 8^{+}$cell protection. A total of 5 mice per group were immunized with $10^{7} \mathrm{CFU}$ of KST0555 orally three times in two-weeks intervals. Mice spleens were isolated at 7 days following the last vaccination, and lymphocytes were prepared from a cell suspension by pressing organ segments through a cell strainer (BD Biosciences). The cell suspension was depleted of red blood cells by using the hypertonic pressure of distilled water and then washed three times with PBS, as previously described (45). Splenic CD4 ${ }^{+}$ and $\mathrm{CD}^{+} \mathrm{T}$ cells were isolated using a $\mathrm{CD} 4^{+} \mathrm{T}$ cell isolation kit (cat. no. 130-104-454; Miltenyi Biotec GmbH) and a CD8 ${ }^{+} \mathrm{T}$ cell isolation kit (cat. no. 130-104-075; Miltenyi Biotec $\mathrm{GmbH}$ ) according to the manufacturer's protocol. Mice serum was isolated as described above and heated at $55^{\circ} \mathrm{C}$ for $30 \mathrm{~min}$ to inactivate the complements. Cell purity was verified to be $>90 \%$ using flow cytometry with staining with phycoerythrin-conjugated anti-mouse CD4 (1:200; cat. no. 100511, BioLegend, Inc.) or FITC-conjugated anti-mouse CD8a (1:200; cat. no. 100705; BioLegend, Inc.) for $15 \mathrm{~min}$ at room temperature. Mouse serum (300 $\mu \mathrm{l}$ per mice), enriched CD4 ${ }^{+}$ $\mathrm{T}$ cells $\left(10^{6}\right.$ cells per mice) or $\mathrm{CD} 8^{+} \mathrm{T}$ cells $\left(10^{5}\right.$ cells per mice $)$ were administered intraperitoneally to each recipient mouse. Subsequent to $24 \mathrm{~h}$, the mice were administered a lethal dose of WT $\left(10^{7} \mathrm{CFU}\right)$, and their mortality and body weight changes were recorded.

Statistical analysis. Data are expressed as the mean \pm standard deviation. Data in the bar graphs and bacterial numbers between groups were compared using an unpaired Student's t-test. The survival of mice was determined using Kaplan-Meier survival analysis, and significance of the difference was analyzed using a Log rank test by using GraphPad Prism software (version 6.0; GraphPad Software, Inc.). $\mathrm{P}<0.05$ was considered to indicate a statistically significant difference.

\section{Results}

Characterization of a ptsI mutant strain (KST0555). Since a previous study indicated that glucose and glycerol are important 

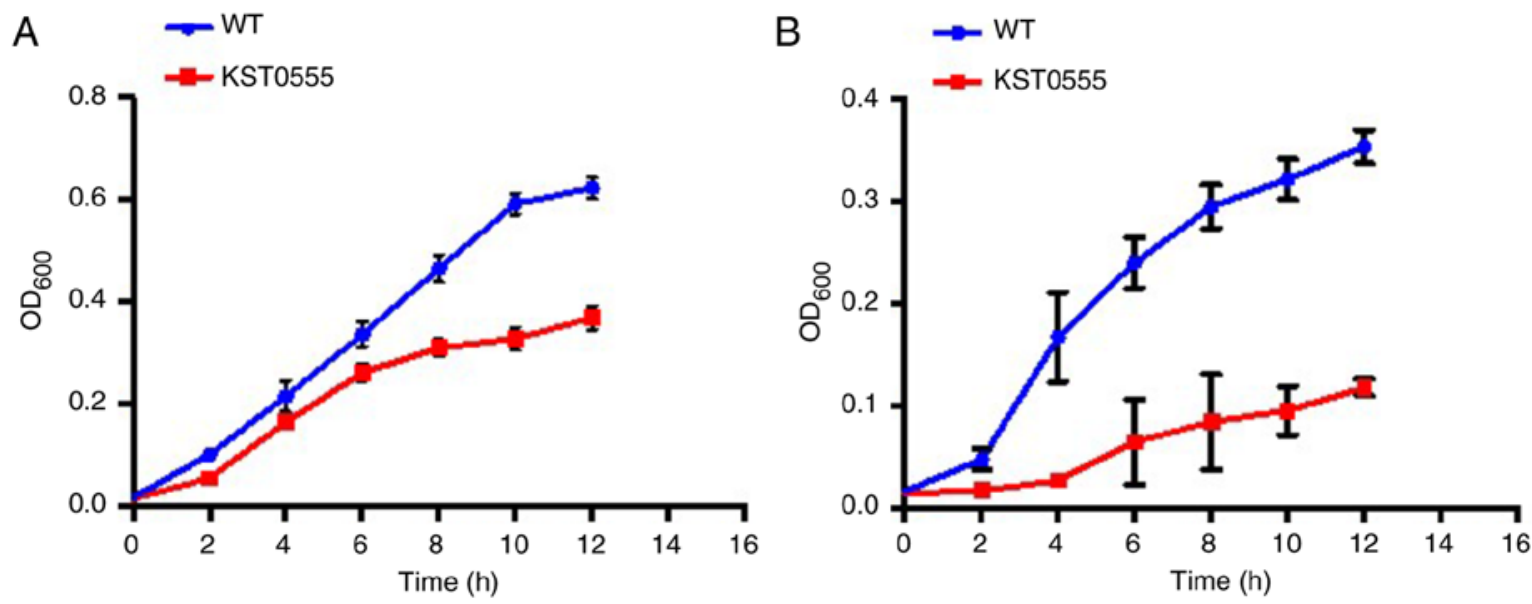

Figure 1. Impaired growth of KST0555 in the minimal M9 broth supplemented with glucose or glycerol. Growth curves of WT (blue) and KST0555 (red) in the minimal M9 broth with (A) $1 \%$ glucose and (B) $1 \%$ glycerol. WT, wild type; OD, optical density.

carbon sources in the systemic infection of Salmonella (30), the growth of KST0555 in minimal medium (M9) supplemented with these carbon sources was examined compared with that of its parent strain. Comparable growth was noted between KST0555 and WT (KST0134) in LB, and each of the strains were unable to grow in M9 medium with no carbon source (data not shown). When KST0555 was cultured in M9 supplemented with glucose, it exhibited substantially lower growth compared with the WT and did not reach the stationary phase in $12 \mathrm{~h}$ (Fig. 1A). Furthermore, its growth in M9 with glycerol was almost abolished (Fig. 1B) indicating that KST0555 was the auxotrophic mutant in the uptake of the carbon source.

Reduction of KST0555 virulence in vitro and in vivo. The present study then investigated the abilities of KST0555 to invade into and replicate within RAW264.7 and IEC- 6 cells. Cell monolayers were infected with Salmonella at a MOI=10, and their relative invasion and replication ratio were calculated at 2 and $18 \mathrm{hpi}$ (Fig. 2A and B). The invasion abilities (at $2 \mathrm{hpi}$ ) of KST0555 to RAW264.7 and IEC-6 cells were reduced significantly compared with that of the WT $(\mathrm{P}<0.005)$. In addition, the replication fold increase of WT were 12.6 \pm 2.9 times and $11.7 \pm 3.2$ times, whereas those of KST0555 were only $1.3 \pm 0.2$ and $1.5 \pm 0.3$ times inside the RAW264.7 and IEC- 6 cells at 18 hpi, respectively $(\mathrm{P}<0.005)$.

To directly visualize the invasion and replication of Salmonella within RAW264.7 cells, immunofluorescence was performed using a FITC-conjugated Salmonella-specific monoclonal antibody (Fig. 2C). A higher density of FITC signals was present in the cell monolayers infected with WT, compared with cells infected with KST0555 at 2 hpi, and the FITC signal was notably increased at $18 \mathrm{hpi}$, indicating efficient invasion and replication in RAW264.7 cells. However, KST0555 was barely detected at 2 and $18 \mathrm{hpi}$. The results were similar with the pattern of intracellular invasion and replication assays presented in Fig. 2A. All results suggest that the expression of ptsI is necessary for invasion and replication in host cells; in other words, its expression is likely required for the intracellular growth of $S$. Typhimurium.

To assess the toxicity of KST0555 in vivo, streptomycin-treated mice $(n=5)$ were infected orally with the indicated doses of WT or KST0555, followed by monitoring of the mortality of mice for 21 days (Fig. 3A and B). When the mice $(n=5)$ were inoculated with $1 \times 10^{7} \mathrm{CFU} / \mathrm{mouse}$ Salmonella WT strain, all mice succumbed to mortality at 10 days subsequent the challenge and their body weight were revealed to substantially decrease day by day. When the mice were inoculated orally with $1 \times 10^{8} \mathrm{CFU} /$ mouse KST0555, the mice exhibited a noticeable drop in their body weight and $40 \%$ of the mice succumbed to mortality. The mice inoculated orally with either $5 \times 10^{7}$ or $1 \times 10^{7} \mathrm{CFU} /$ mouse doses did not succumb to mortality, but the mice inoculated orally with $5 \times 10^{7} \mathrm{CFU} /$ mouse exhibited a noticeable body weight loss by day 3 and exhibited a slow recovery in weight from day 11, indicating that the lethal dose $50\left(\mathrm{LD}_{50}\right)$ of KST0555 was $\sim 10^{8} \mathrm{CFU} /$ mouse, but the optimal oral vaccination dose in mice was lower compared with $1 \times 10^{7} \mathrm{CFU} /$ mouse.

Salmonella infections typically are initiated by the ingestion of contaminated food and water, followed by the successful colonization in the distal ileum $(46,47)$. The present study initially examined the colonized Salmonella in the mice organs at the time of mortality or $72 \mathrm{~h}$ subsequent to the oral inoculation of $1 \times 10^{7} \mathrm{CFU}$ bacteria (Fig. 3C). Mice infected with the WT strain revealed substantially greater numbers of colonized Salmonella, estimated between $10^{8}$ and $10^{9} \mathrm{CFU} / \mathrm{g}$, which was higher compared with the number of infection, indicating infected Salmonella colonized and replicated in the mice intestine. In contrast, it was revealed that there was $<10^{6} \mathrm{CFU} / \mathrm{g}$ Salmonella in the cecum of the mice infected with KST0555 at the time of mortality or 72 hpi.

Colonized Salmonella are occasionally translocated to systemic sites or to the peritoneal cavity to cause iNTS (48). The present study further examined the levels of Salmonella colonization in mice mesenteric lymphnodes, spleen, and blood (Fig. 3D-F) at the time of mortality or $72 \mathrm{hpi}$. A total of $>10^{5}-10^{9} \mathrm{CFU} /$ tissue or CFU/ml Salmonella were detected in the mice organs and blood infected with WT, but no or $<10^{4} \mathrm{CFU} /$ tissue or CFU/ml Salmonella were detected in mice organs and blood infected with KST0555, indicating that the KST0555 strain is attenuated and causes less pathological symptoms in vivo. 

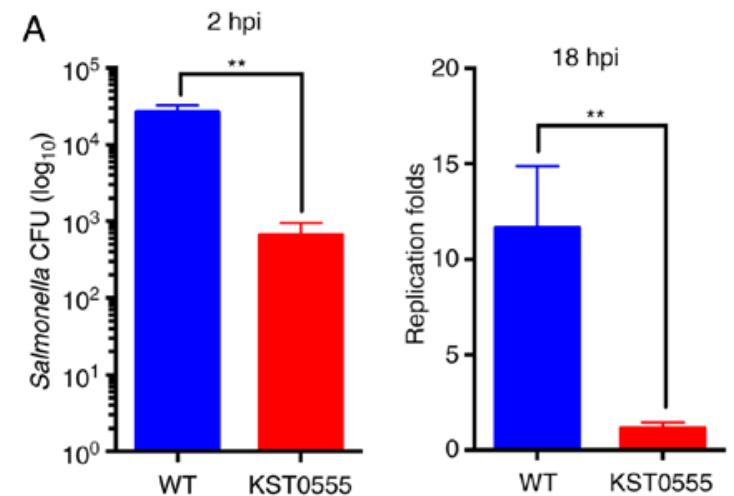

C
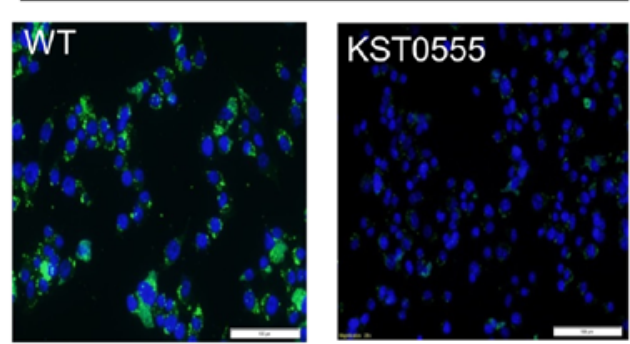
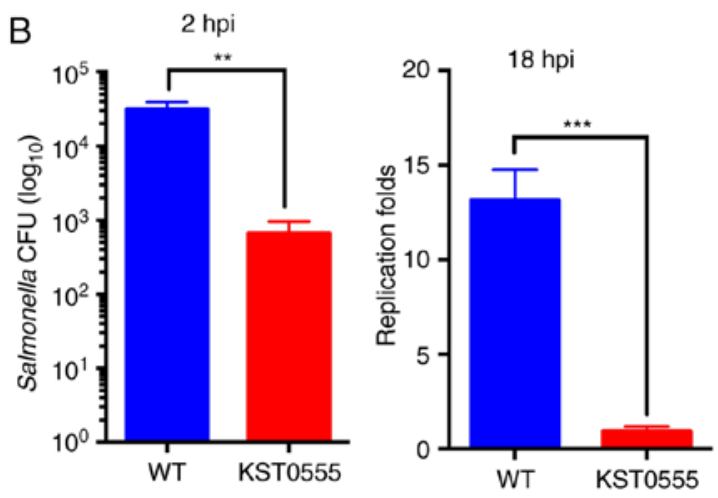

$18 \mathrm{hpi}$
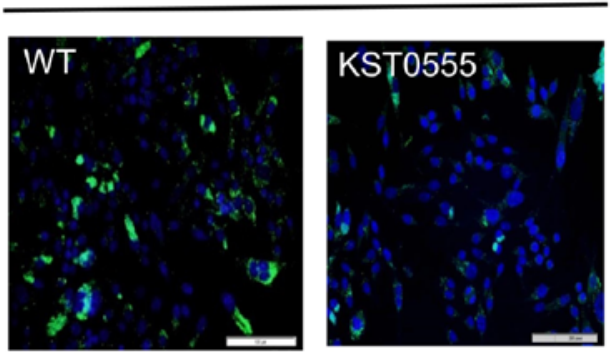

Figure 2. Importance of ptsI expression for Salmonella invasion and replication in mouse macrophages and epithelial cells. (A) Macrophages (RAW264.7 cells) or (B) IEC-6 cells were infected with WT or KST0555 at a multiplicity of infection of 10 and bacterial viability were counted at 2 or 18 hpi. Relative invasion and replication fold of KST0555 were calculated by comparing with WT. Data are representative of three independent experiments and are presented as the mean \pm standard deviation. ${ }^{* *} \mathrm{P}<0.005$ and ${ }^{* * *} \mathrm{P}<0.001$ with comparisons shown by lines. (C) Adherence and invasion of Salmonlla were visualized using an immunofluorescence assay. WT or KST0555 infected RAW264.7 cells were stained with fluorescein isothiocyanate-conjugated Salmonella-specific immunoglobulin G (green) at 2 or $18 \mathrm{hpi}$. Scale bar, $100 \mu \mathrm{m}$. Nuclei were stained with DAPI (blue). IEC, intestinal epithelial cells; WT, wild type; hpi, hours post-infection; CFU, colony forming unit.

Downregulation of virulence-associated genes in KST0555. Next, the present study investigated the effect of the ptsI mutation on flagella expression and Salmonella motility. Surprisingly, only the expression of the $f i C$ gene encoding a main flagellin subunit was significantly reduced by $95 \pm 3.7 \%$ in KST0555 compared with that in WT ( $\mathrm{P}<0.005)$; however, $f h D$, $f i i A, f l Z$ and $f l g M$ were not significantly reduced (Fig. 4A). To verify whether the downregulation of $f i C$ effectively influenced the motility of Salmonella, stationary phase cultures of WT or KST0555 were inoculated on motility agar medium followed by monitoring Salmonella migration diameters on agar plates following $18 \mathrm{~h}$ of incubation. Even though only $\mathrm{fiC}$ gene expression was impaired in KST0555, it exhibited significantly smaller halos compared with those of WT $(\mathrm{P}<0.001$; Fig. 4B).

To determine whether the substantial reduction of a virulence phenotype in KST0555 was due to the downregulation of major virulent genes in Salmonella, the expression of the genes encoded in SPI-1 and -2 were examined, which have been attributed to numerous virulence properties of Salmonella $(49,50)$. The majority of genes encoded within SPI-1 are well known to serve an active function in penetration into the intestinal epithelial barrier, and the expression of SPI-1 genes are regulated by the fundamental transcriptional regulators HilA, HilD and InvF (51). Thus, the present study firstly compared the expression of HilA and HilD proteins, central regulators of SPI-1 genes. As revealed in Fig. 4C, the expression of each of these proteins was reduced in KST0555 compared with in WT. In addition, inv $F$ mRNA levels, regulated by HilA and HilD, were significantly downregulated in KST0555 compared with in WT, which explains why invF-dependent $\operatorname{sip} B C D A$ mRNA expression levels were reduced by $\sim 80 \%$ in KST0555 compared with in WT ( $\mathrm{P}<0.001$; Fig. 4D).

HilD is also known to activate SPI-2 genes, the key virulence determinants for the survival/replication of Salmonella inside the host cells, through inducing the expression of the SsrA/B two-component system, the central positive regulator of SPI-2 (52). Thus, the expression of the key virulence factor sseA was compared in WT, KST0555 and KST0583 $(\Delta h i l D)$ grown in LB or LPM using the lac $Z$ gene fused to the promoter of sseA. As expected, the sseA expression was almost abolished in $\Delta$ hilD grown in only LB, whereas its expression was similar with WT when cultured in LPM, SPI-2 gene expression media (Fig. 4E and F). However, no sseA expression was revealed in KST0555 culture in LB and LPM. The expression levels of the downstream genes of the SseA promoter (SsaB, SsaG, SsrA and SseA) were examined using RT-qPCR. As shown in Fig. 4G, these genes were significantly downregulated in KST0555 culture in LB compared with the WT $[s s a B(\mathrm{P}=0.001), s s a G(\mathrm{P}=0.0003), s s r A(\mathrm{P}=0.0047)$ and sseA $(\mathrm{P}=0.0095)]$. These results suggest that the reduced SPI-2 expression in KST0555 was in part due to the lower expression of HilD by a ptsI mutation, and additional mechanism(s) may be responsible for the downregulation of SPI-2 expression other than HilD in KST0555.

Vaccination of KST0555 elicits protective immune response against Salmonella. To determine whether KST0555 may be 

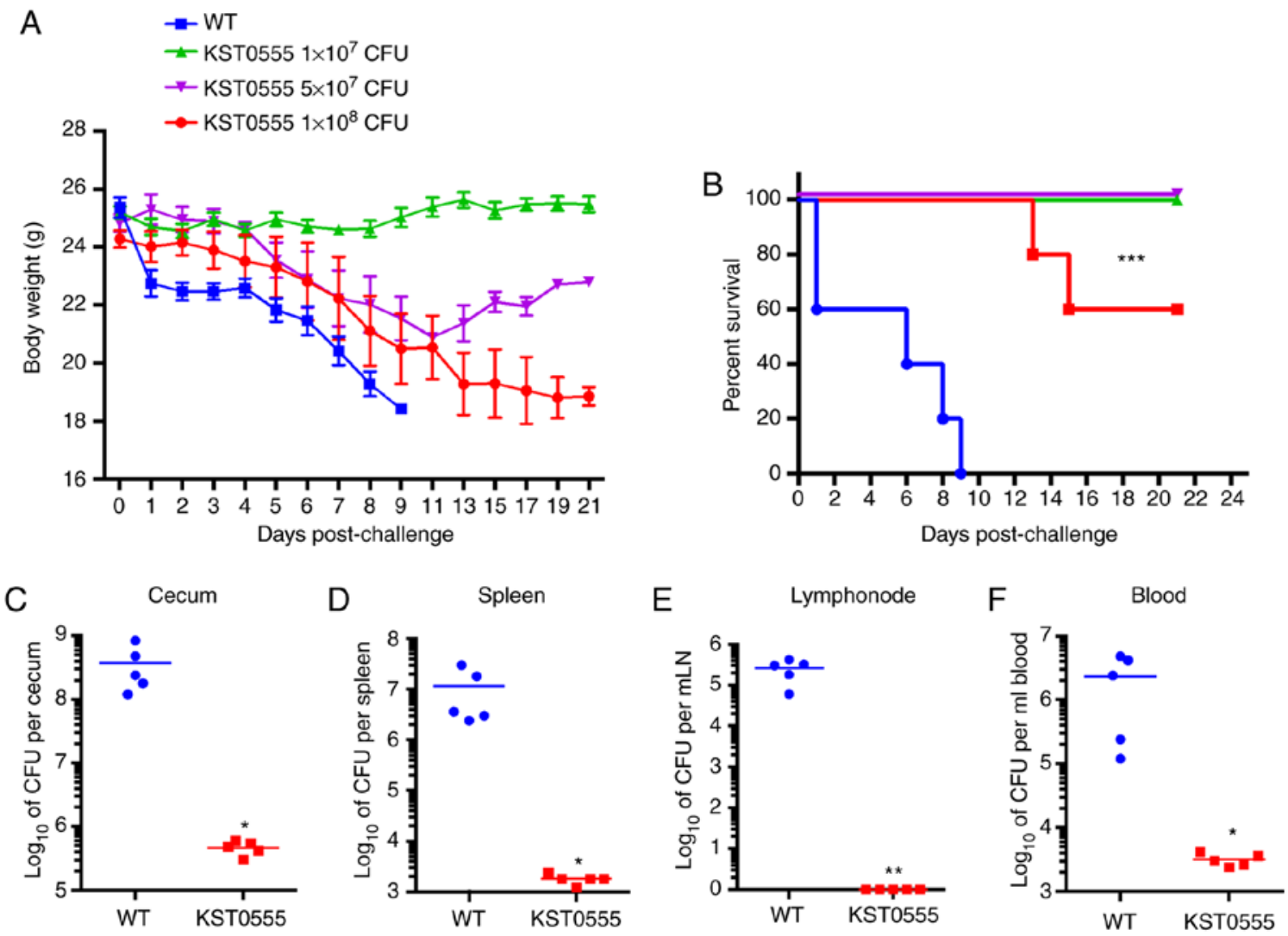

Figure 3. Virulence of KST0555 in a mouse colitis model. Survival curve of BALB/c mice $(n=5)$ were pretreated with 20 mg streptomycin, followed by inoculation orally with $1 \times 10^{7}, 5 \times 10^{7}$ and $1 \times 10^{8}$ CFU KST0555 and $1 \times 10^{7}$ CFU WT. (A) Mice survival and (B) body weight change was monitored for 21 days. Mice organs were dissected at the time of mortality or 72 hpi. The number of bacteria in the (C) cecum, (D) mLN, (E) spleen and (F) blood were counted. Data were presented as the mean \pm standard deviation. ${ }^{*} \mathrm{P}<0.05,{ }^{* *} \mathrm{P}<0.05$ and ${ }^{* * * *} \mathrm{P}<0.001$ vs. WT. CFU, colony forming unit; WT, wild type; hpi, hours post-infection; $\mathrm{mLN}$, mesenteric lymph nodes.

used as a live oral vaccine, the mice were immunized orally $(\mathrm{n}=5)$ three times in two-week intervals $(0,2$ and 4 weeks) with $10^{7} \mathrm{CFU}$ of KST0555 and the levels of Salmonella and Salmonella LPS-specific antibodies in the serum were determined at 7 days following the last immunization (5 weeks). As presented in Fig. 5A, KST0555 vaccination significantly enhanced the serum levels of Salmonella-specific IgG (mean titer $=1024)$ and $\mathrm{IgM}$ (mean titer=288) compared with those of PBS-immunized mice (mean titer $=36-72 ; \mathrm{P}<0.05$ ). LPS-specific IgG and IgM were also elevated significantly by KST0555 vaccination compared with PBS-treated mice ( $\mathrm{P}<0.05$; Fig. 5B). When the subclasses of IgG specific for Salmonella (Fig. 5C) and LPS (Fig. 5D) were analyzed, Salmonella and LPS specific-IgG1, IgG2a, IgG2b and IgG3 were significantly increased compared with those of PBS groups $(\mathrm{P}<0.05)$. In addition, significant increases in $\mathrm{Th} 1$ and Th2-spcific cytokines (IFN- $\gamma$ and IL-4) were detected in splenocytes from mice immunized with KST0555 when compared with PBS-immunized control mice $(\mathrm{P}<0.05)$ indicating that live KST0555 vaccine induces high antigen-specific antibody responses and T-cell mediated immune responses (Fig. 5E and F).

To directly determine the protective effect of a live KST0555 vaccine, the immunized mice were challenged orally with $10^{7} \mathrm{CFU}$ of WT at 7 days following the last vaccination (week 5). All PBS-immunized mice succumbed to mortality in 12 days post-injection along with a substantial reduction of body weight daily, but $100 \%$ of KST0555-immunized mice were alive for $>14$ days post-injection without an obvious change in body weight (Fig. 5G and H). This suggests that a live KST0555 vaccine may provide a protective immune response.

Protection by adoptive transfer of serum, $C D 4^{+}$or $C D 8^{+}$ $T$ cells. The present study then investigated whether a live KST0555 vaccine may elicit functional humoral and cell-mediated immunities by an adoptive transfer experiment. Five mice in each group were administered intraperitoneally with $300 \mu 1$ serum, $1 \times 10^{6} \mathrm{CD}^{+} \mathrm{T}$ cells or $1 \times 10^{5} \mathrm{CD} 8^{+} \mathrm{T}$ cells isolated from unvaccinated or live KST0555 ( $\left.1 \times 10^{7} \mathrm{CFU}\right)$ vaccinated mice as described above, followed by challenging with $10^{7} \mathrm{CFU}$ of WT Salmonella. Mice receiving the serum from live KST0555 immunized mice survived significantly longer compared with mice receiving unimmunized serum $(\mathrm{P}=0.0042$; Fig. $6 \mathrm{~A})$, indicating that the antibodies raised by KST0555 vaccination were functional. The mice receiving splenic $\mathrm{CD}^{+} \mathrm{T}$ cells from KST0555-immunized mice survived 2 or 3 days longer compared with the naïve group, which was not significant, but modestly protected $(\mathrm{P}=0.0547$; Fig. $6 \mathrm{~B})$. The mice receiving splenic $\mathrm{CD}^{+} \mathrm{T}$ cells from KST0555-immunized mice exhibited significant and sufficient protection compared with the transfer of those from the naïve group ( $\mathrm{P}=0.0015$; Fig. 6C), suggesting that a live oral KST0555 vaccine might induce an efficient cell-mediated immune response. 
A $\quad$ WT $\square$ KST0555

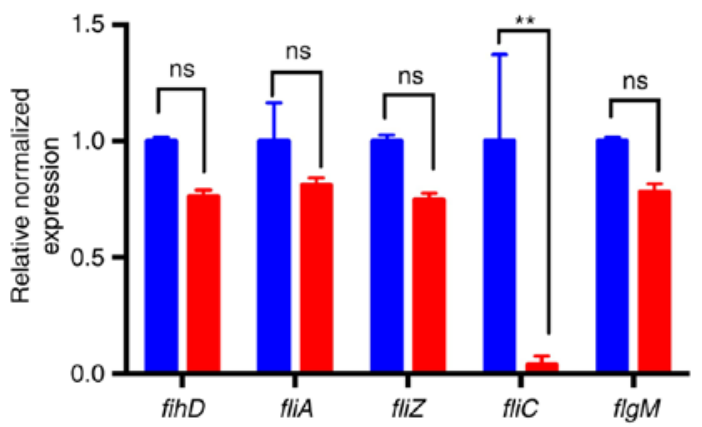

B

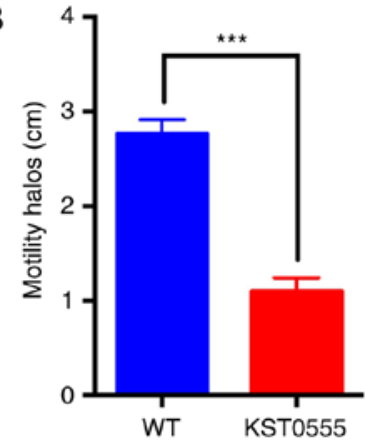

C

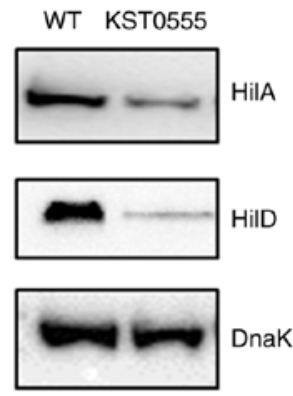

D
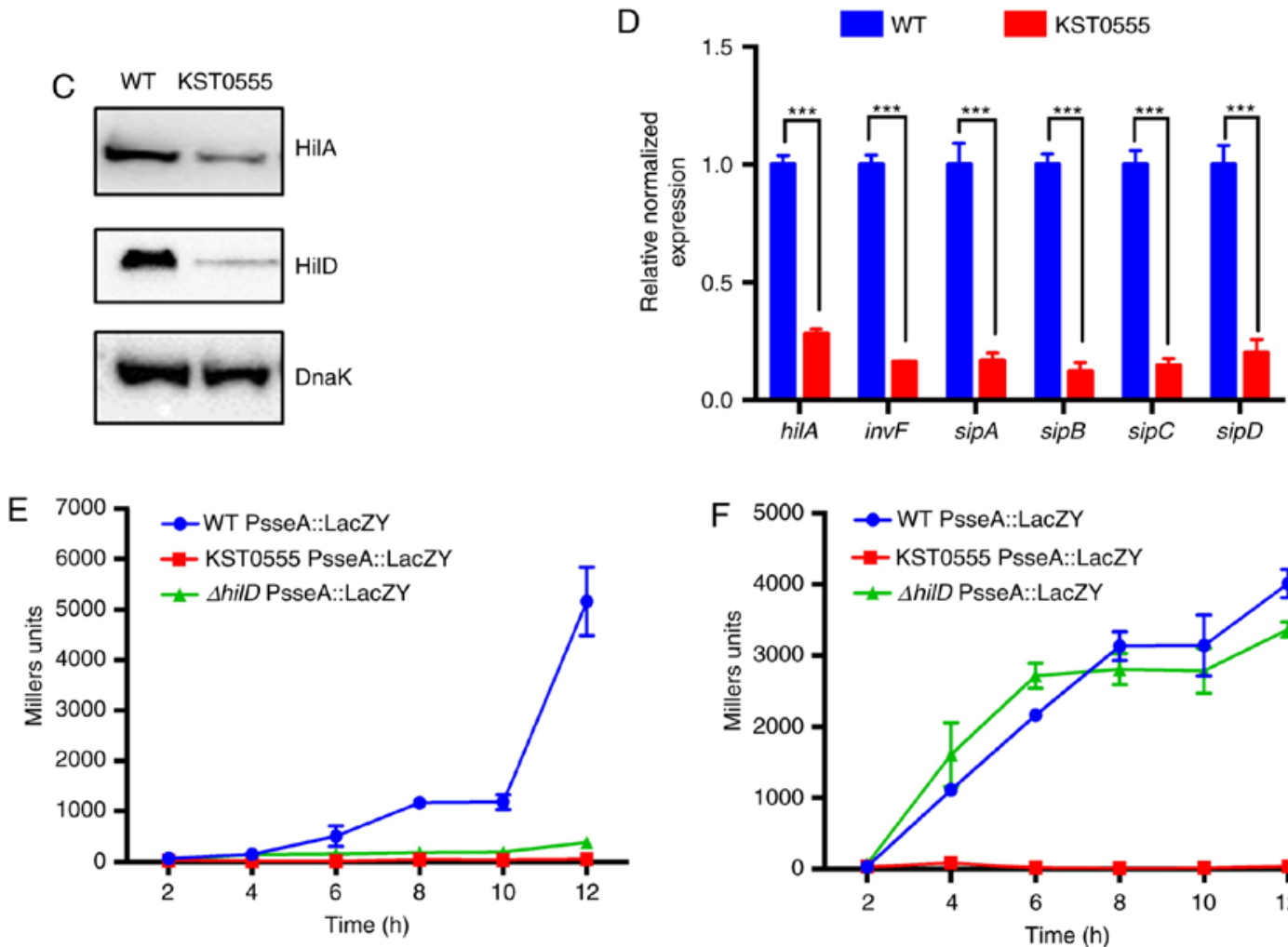

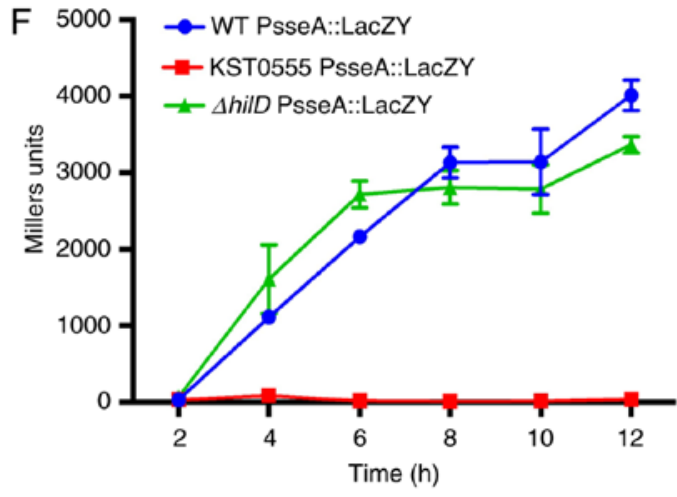

KST0555

G

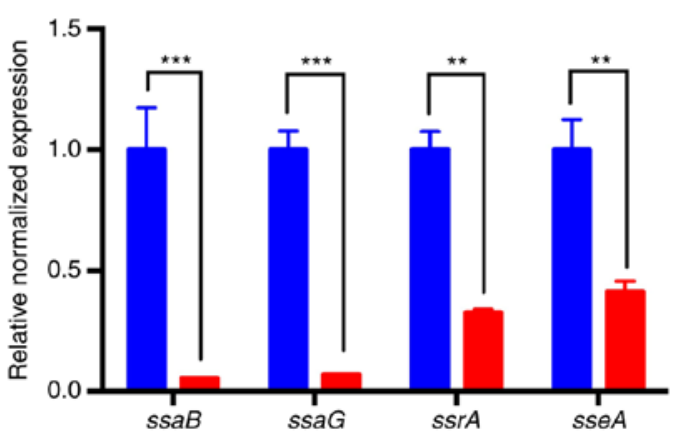

Figure 4. Downregulation of virulent genes and key regulator proteins of Salmonella in T3SS. Lower mobility caused by the deletion of the ptsI gene. (A) mRNA expression levels of flagella biosynthesis genes, $f h D$, fliA, fliZ, fliC and $f l g M$ in WT and KST0555 at early-log phase in LB broth were measured using RT-qPCR. (B) Salmonella motility was measured on an agar plate by inoculating $10 \mu \mathrm{l}$ WT or KST0555 culture broth. The zone size of motility was measured at $18 \mathrm{~h}$ following inoculation. (C) Protein expression of Salmonella T3SS key regulators (HilA and HiD) in WT and KST0555 was examined using a HilA::FLAG and HilD::HA chromosomal fusion system. (D) Reduced expression of Salmonella SPI-1 genes and their regulators in KST0555. The expression of SPI-1 encoded genes (hilA, invF, sopA, sipB, sipC and $\operatorname{sip} D$ ) in WT and KST0555 at the early-log phase in LB broth was quantified using RT-qPCR compared with that in WT. Reduced key virulence factor sseA expression in KST0555 and $\Delta$ hilD was abolished, compared with that in WT grown in (E) LB using the lacZ gene fused to the promoter of sseA, but only KST0555 still exhibited no expression of sseA, compared with $\triangle$ hilD and WT grown in (F) LPM. (G) Downregulation of SPI-2 encoded genes in KST00555. Transcription levels of SPI-2 encoded genes of KST0555 in LPM were quantified using RT-qPCR compared with that in WT. Data are representative of three independent experiments and presented as the mean \pm standard deviation. Asterisks indicate significant differences between WT and KST0555. ${ }^{* *} \mathrm{P}<0.05$ and ${ }^{* * * *} \mathrm{P}<0.001$ with comparisons shown by lines. WT, wild type; RT-qPCR, reverse transcription-quantitative PCR; LB, Luria-Bertani broth; LPM, MES-buffered minimum media; ns, non-significant. 

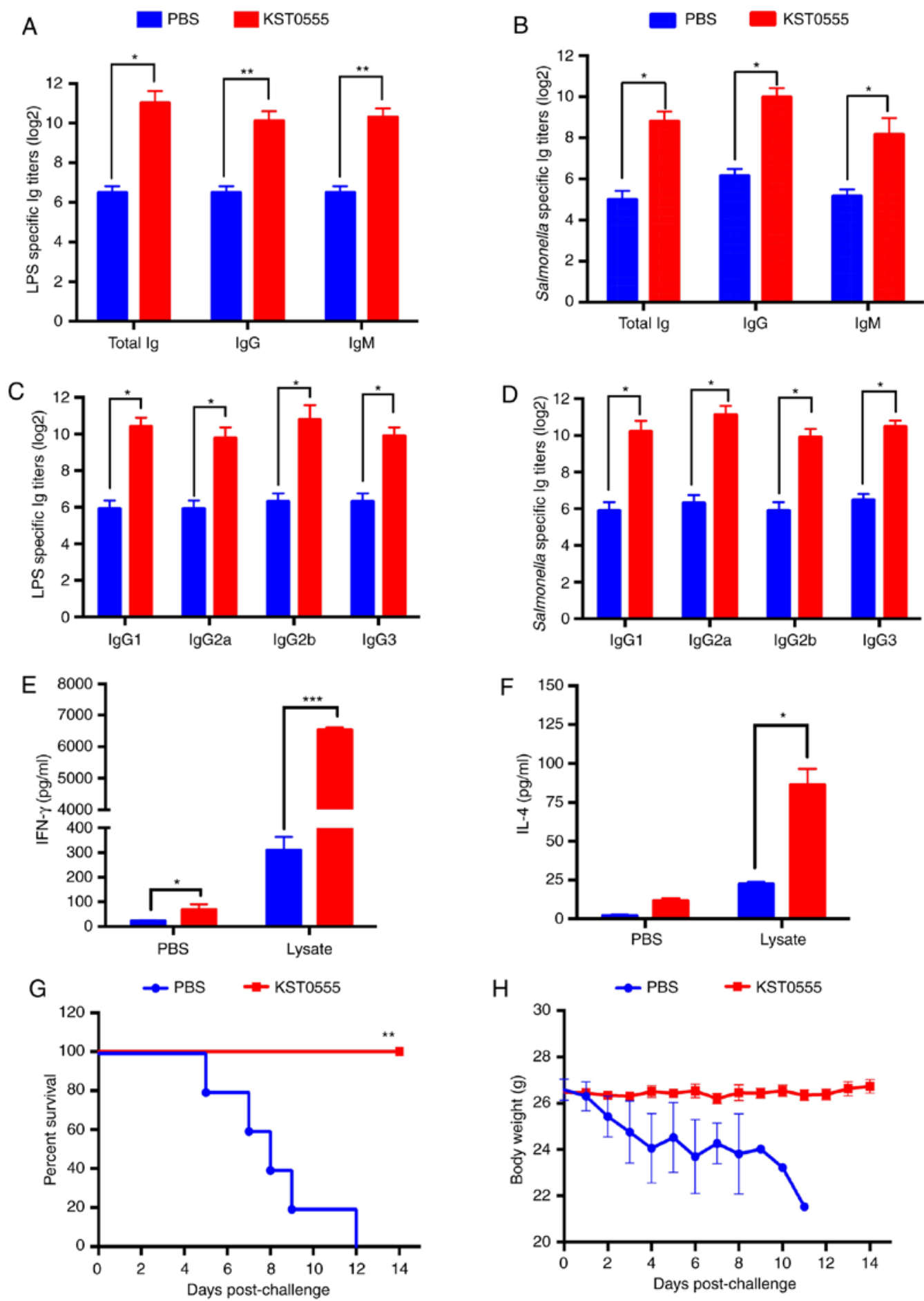

Figure 5. Protective effect of KST0555 immunization against Salmonella infections in mice. BALB/c mice ( $\mathrm{n}=5$ ) were orally immunized with KST0555 or PBS three times at two-week intervals. Serum levels of (A) Salmonella- or (B) LPS-specific total Ig, IgG and IgM were analyzed at 7 days following the last immunization. Data are representative of three independent experiments and are presented as the mean \pm standard deviation. Subclass levels of (C) Salmonellaand (D) LPS-specific IgG1, IgG2a, IgG2b and IgG3 were analyzed at 7 days subsequent to the last immunization. Data are representative of three independent experiments and are presented as the mean \pm standard deviation. Splenocytes isolated from mice were incubated with $10^{8} \mathrm{CFU}$ of $S$. Typhimurium WT lysate for $72 \mathrm{~h}$, and concentrations of (E) IFN- $\gamma$ and (F) IL-4 were measured from culture supernatants using an enzyme-linked immunosorbent assay. Bars indicate the mean of results of triplicate wells of a representative experiment. Error bars indicate standard deviation. Immunized mice were challenged orally with $10^{7} \mathrm{CFU}$ of WT at 7 days following the last immunization and $(\mathrm{G})$ mouse survival and (H) body weight were monitored for 14 days. " $\mathrm{P}<0.05$, ${ }^{* * *} \mathrm{P}<0.005$ and ${ }^{* * *} \mathrm{P}<0.001$ vs. PBS group. PBS, phosphate buffered saline; Ig, immunoglobulin; LPS, lipopolysaccharide; CFU, colony-forming units; WT, wild-type; IFN- $\gamma$, interferon- $\gamma$; IL-4, interleukin-4.

\section{Discussion}

NTS infection is the leading cause of mortality in Africa and other developing countries (3). Previous comprehensive epidemiological studies of iNTS indicate the urgent need of novel therapeutic methods for these infections $(3,4,53)$. Live attenuated vaccines against NTS are a promising solution for the spreading of NTS, because they have numerous advantages 

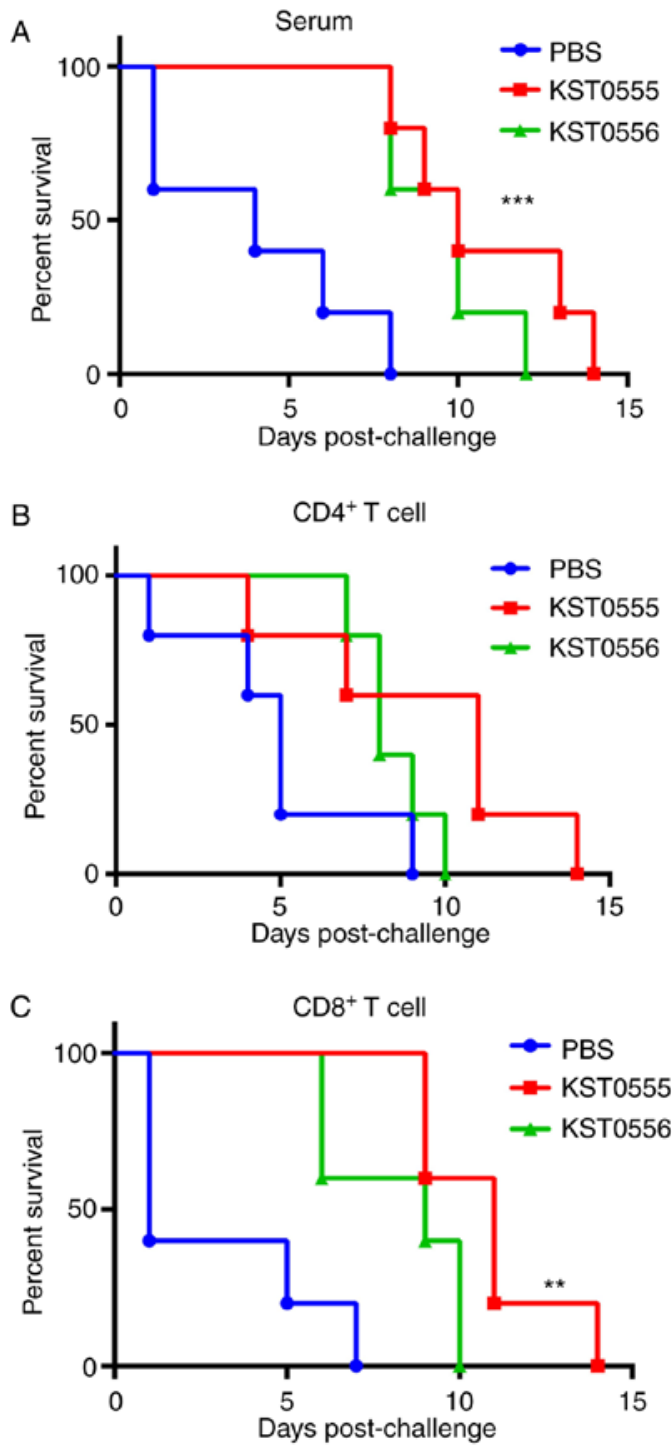

Figure 6. Protection by the adopted transfer of KST0555-vaccinated mice serum and $\mathrm{CD}^{+} \mathrm{T}$ cells against Salmonella infection. (A) Serum $(300 \mu 1)$ from PBS or KST0555-immunized mice was inoculated intraperitoneally into naïve $\mathrm{BALB} / \mathrm{c}$ mice $(\mathrm{n}=5)$. At $12 \mathrm{~h}$ following inoculation, mice were challenged orally with $10^{7} \mathrm{CFU}$ of WT. Mouse survival was monitored for 14 days. Mice were immunized with KST0555 three times at 14-day intervals orally, and the spleen was dissected from the mice 7 days following final immunization. (B) Splenic $\mathrm{CD} 4^{+} \mathrm{T}$ cells or $(\mathrm{C}) \mathrm{CD}^{+} \mathrm{T}$ cells from PBS- or KST0555-immunized mice were transferred intraperitoneally to naïve $\mathrm{BALB} / \mathrm{c}$ mice $(\mathrm{n}=5)$. At $12 \mathrm{~h}$ following inoculation, mice were challenged orally with $107 \mathrm{CFU}$ of WT, and mouse survival was monitored for 14 days ${ }^{* *} \mathrm{P}<0.05$ and ${ }^{* * *} \mathrm{P}<0.001$ vs. the PBS group. PBS, phosphate buffered saline; CFU, colony-forming units; WT, wild-type.

over other vaccine types, including cost-effective production, induction of mucosal and cell-mediated immunities and no hazardous waste (21). In the present study, it was hypothesized that the disruption of ptsI in $S$. Typhimurium may create an attenuated strain, which is efficacious for vaccine application, by interfering with the uptake of PTS sugars, particularly glucose, the predominant carbohydrate source during infection. This strain, deficient in the uptake of PTS (glucose) and non-PTS (glycerol) sugars, exhibited a significantly $(\mathrm{P}=0.0172)$ reduced virulence in vitro and in vivo and elicited effective humoral and cell-mediated immune responses to protect against Salmonella infection.
The vaccine strain attenuated in metabolic gene(s) requires being metabolically active to reach immune inductive sites and elicit a biologically relevant protective immunity in the absence of overt disease. Furthermore, the hyperattenuation of vaccine strains may require the administration of multiple oral doses to achieve an effectively protective immune response $(54,55)$. The deletion of $a r o A$, a gene of the shikimate pathway associated with the synthesis of aromatic amino acids, is most commonly used as a metabolic mutation to attenuate Salmonella (56). The guaBA gene-deleted vaccine candidates, which impair guanine biosynthesis, are based on $S$. Typhimurium and $S$. Enteritidis isolates from sub-Saharan Africa; preclinical studies were conducted using a series of Center for Vaccine Development (University of Maryland School of Medicine) by using relevant animal models for human gastroenteritis, including streptomycin-pretreated mouse and rhesus macaque models $(20,21)$. Another approach for developing live attenuated vaccines is the deletion of genes involved in the uptake of essential elements or nutrients that are indispensable for the growth of infectious microorganisms. In one example, the mutant in the $z n u A B C$ operon encoding the high-affinity zinc transporter was revealed to be a safe and efficacious vaccine candidate in the setting of mouse and pig vaccine models (57-60).

In a previous study, the extreme attenuation was achieved by deleting two components genes, ptsI and $c r r$ genes, in PTS, despite the fact that a high number $\left(>1 \times 10^{9} \mathrm{CFU}\right)$ of $\Delta$ ptsIcrr was administrated without a noticeable body weight loss and its humoral immune responses may protect against a lethal challenge of its parent strain (34). However, the hyperattenuation of the $\Delta$ ptsIcrr strain also result in a high dose of CFU being needed, along with the non-activation of cell-mediated immune responses (34). In the present study, the KST0555 strain was defective in only one sugar transport gene (ptsI), but also highly attenuated in the mouse model. Although its targeting to immune sites, including spleen and mesenteric lymph nodes, was substantially reduced compared with that of the parent strain, its immune responses were sufficient to provide the protection against Salmonella infection via both humoral and cellular immunity.

In fact, numerous live attenuated Salmonella vaccine strains under pre-clinical and clinical studies have been revealed to have associations between the transcriptional and translational expression for two notable groups of virulence genes, SPI-1 and SPI-2 (21,24,61-63). Each are essential for colonization, invasion and intracellular proliferation and thus contribute to the successful infection of $S$. Typhimurium into the host cells by assembling T3SS (64). PTS is the most well-known and important carbon uptake system consisting of two general components: Enzyme I (EI) encoded by ptsI and histidine phosphocarrier protein ( $\mathrm{HPr}$ ) encoded by $\mathrm{pts} H$ and the membrane-associated EII complex. EII complexes, consisting of the EIIA, EIIB and EIIC proteins, are usually carbon-specific; for example, EIIA ${ }^{\mathrm{Glc}}$ encoded by $\mathrm{cr}$ stands for the glucose-specific EIIA component (65). The first PTS component, PtsI, autophosphorylates by using phosphoenolpyruvate as a phosphoryl donor and transfers the phosphate group through HPr to the EII complex to trigger the uptake of PTS sugars, including glucose, mannose, mannitol, fructose and cellobiose (33). Further evidence suggests that virulence functions and metabolism of pathogens are intertwined 
by global regulatory networks, which serve an important function in the regulation of virulence traits (66). The SirA/BarA two-component system involved in various cellular responses, including carbohydrate metabolism, motility, biofilm formation and stress survival, may regulate the expression of SPI-1 and SPI-2 genes alone with the carbon storage regulatory ( $c s r)$ systems $(67,68)$. Since the expression of $\operatorname{sir} A$ and $\operatorname{csr} A$ is reduced by the mutation of the adenylate cyclase gene, which synthesizes cyclic AMP (cAMP) from ATP, or the cAMP receptor protein gene (crp) in $S$. Typhimurium (67) and deletion of the ptsI gene, prevents the formation of phosphorylated EIIA ${ }^{\mathrm{Glc}}$, the activator of adenylate cyclase, the reduction of SPI-1 and SPI- 2 gene expression in KST0555 ( $\Delta p t s I)$ is likely to be partially mediated via the cAMP/crp regulation mechanism (69). In addition, it was revealed that the reduction of virulence in KST0555 was not entirely due to the downregulation of SPI genes. One novel result was that only the $\mathrm{fliC}$ gene of the five flagella-associated genes tested was significantly downregulated in KST0555, which impaired Salmonella motility. Flagella-mediated motility is known to be required for the efficient colonization and induction of colitis in mice $(70,71)$. Thus, further investigation on the mechanisms by which ptsI mutation affects the flagella gene expression of $S$. Typhimurium is warranted. The notable downregulation of SPI-1 and SPI-2 genes in ptsI mutants reveals the advantage of this mutant strain as an attenuated vaccine candidate. However, the comparison of the immunological efficacy of this strain with previously well-characterized vaccine strains and the regulation axis between carbon uptake and virulence in Salmonella should be investigated further at the molecular level.

In summary, the present study provides further strong evidence that the carbon transport system is an excellent target to develop a live Salmonella vaccine. Since the reduced virulence of KST0555 amy be attributed to not only the impairment of the sugar uptake but also the downregulation of virulence genes including SPI and flagellin, the molecular mechanism of the association between virulence and PTS should be studied further. However, these promising preclinical data provide a strong rationale for the advancement of KST0555 as a vaccine candidate. Furthermore, since PTS is widely conserved in gram-negative and gram-positive bacteria, the present study offers a novel insight for developing novel vaccine strains against various pathogenic bacteria.

\section{Acknowledgements}

Not applicable.

\section{Funding}

The present study was supported by the National Research Foundation of Korea (grant nos. NRF-2017M2A2A6A020 20925 and NRF-2018K2A9A2A06023828 to HSS) and the Nuclear R\&D Program of the Ministry of Science, ICT \& Future Planning (to SL).

\section{Availability of data and materials}

The data used and/or analyzed in this study are available from the corresponding author upon reasonable request.

\section{Authors' contributions}

YZ and HSS conceived and designed the experiments. YZ, HSS, SML, KBA and HJJ performed the experiments. YZ, HSS, KBA, HCG, SR and SL analyzed the data. YZ, HSS, KBA and SL wrote the manuscript. All authors read and approved the final manuscript.

\section{Ethics approval and consent to participate}

The animal experiments were ethically approved by the Committee on The Use and Care of Animals at the Korea Atomic Energy Research Institute and performed according to accepted National Health Institute standards.

\section{Patient consent for publication}

Not applicable.

\section{Competing interests}

The authors declare that they have no competing interests.

\section{References}

1. Abed N, Grepinet O, Canepa S, Hurtado-Escobar GA, Guichard N, Wiedemann A, Velge P and Virlogeux-Payant I: Direct regulation of the pefI-srgC operon encoding the Rck invasin by the quorum-sensing regulator SdiA in Salmonella Typhimurium. Mol Microbiol 94: 254-271, 2014.

2. Febriani Y, Levallois P, Gingras S, Gosselin P, Majowicz SE and Fleury MD: The association between farming activities, precipitation, and the risk of acute gastrointestinal illness in rural municipalities of Quebec, Canada: A cross-sectional study. BMC Public Health 10: 48, 2010.

3. Ao TT, Feasey NA, Gordon MA, Keddy KH, Angulo FJ and Crump JA: Global burden of invasive nontyphoidal Salmonella disease, 2010(1). Emerg Infect Dis 21, 2015.

4. Feasey NA, Dougan G, Kingsley RA, Heyderman RS and Gordon MA: Invasive non-typhoidal Salmonella disease: An emerging and neglected tropical disease in Africa. Lancet 379: 2489-2499, 2012.

5. Crump JA, Sjolund-Karlsson M, Gordon MA and Parry CM: Epidemiology, clinical presentation, laboratory diagnosis, antimicrobial resistance, and antimicrobial management of invasive Salmonella infections. Clin Microbiol Rev 28: 901-937, 2015.

6. Zansky S, Wallace B, Schoonmaker-Bopp D, Smith P, Ramsey F, Painter J, Gupta A, Kalluri P and Noviello S: From the centers for disease control and prevention. Outbreak of multi-drug resistant Salmonella Newport-United States, January-April 2002. JAMA 288: 951-953, 2002.

7. Strugnell RA, Scott TA, Wang N, Yang C, Peres N, Bedoui S and Kupz A: Salmonella vaccines: Lessons from the mouse model or bad teaching? Curr Opin Microbiol 17: 99-105, 2014.

8. Typhoid vaccines: WHO position paper. Wkly Epidemiol Rec 83: 49-59, 2008 (In English, Finnish).

9. DeRoeck D, Ochiai RL, Yang J, Anh DD, Alag V and Clemens JD: Typhoid vaccination: The Asian experience. Expert Rev Vaccines 7: 547-560, 2008.

10. DeRoeck D, Clemens JD, Nyamete A and Mahoney RT: Policymakers' views regarding the introduction of new-generation vaccines against typhoid fever, shigellosis and cholera in Asia. Vaccine 23: 2762-2774, 2005.

11. Kantele A, Pakkanen SH, Siitonen A, Karttunen R and Kantele JM: Live oral typhoid vaccine Salmonella Typhi Ty21a-a surrogate vaccine against non-typhoid salmonella? Vaccine 30: 7238-7245, 2012.

12. Watson DC, Robbins JB and Szu SC: Protection of mice against Salmonella typhimurium with an O-specific polysaccharide-protein conjugate vaccine. Infect Immun 60: 4679-4686, 1992. 
13. Gerke C, Colucci AM, Giannelli C, Sanzone S, Vitali CG, Sollai L, Rossi O, Martin LB, Auerbach J, Di Cioccio V and Saul A: Production of a shigella sonnei vaccine based on generalized modules for membrane antigens (GMMA), 1790GAHB PLoS One 10: e0134478, 2015.

14. Secundino I,Lopez-Macias C,Cervantes-Barragan L, Gil-CruzC, Ríos-Sarabia N, Pastelin-Palacios R, Villasis-Keever MA, Becker I, Puente JL, Calva E and Isibasi A: Salmonella porins induce a sustained, lifelong specific bactericidal antibody memory response. Immunology 117: 59-70, 2006.

15. Kodama $\mathrm{C}$ and Matsui $\mathrm{H}$ : Salmonella flagellin is not a dominant protective antigen in oral immunization with attenuated live vaccine strains. Infect Immun 72: 2449-2451, 2004.

16. Gil-Cruz C, Bobat S, Marshall JL, Kingsley RA, Ross EA, Henderson IR, Leyton DL, Coughlan RE, Khan M, Jensen KT, et al: The porin OmpD from nontyphoidal Salmonella is a key target for a protective B1b cell antibody response. Proc Natl Acad Sci USA 106: 9803-9808, 2009.

17. Sette A and Rappuoli R: Reverse vaccinology: Developing vaccines in the era of genomics. Immunity 33: 530-541, 2010

18. Salazar-Gonzalez RM, Maldonado-Bernal C, Ramirez-Cruz NE, Rios-Sarabia N, Beltrán-Nava J, Castañón-González J, Castillo-Torres N, Palma-Aguirre JA, Carrera-Camargo M, López-Macías C and Isibasi A: Induction of cellular immune response and anti-Salmonella enterica serovar typhi bactericidal antibodies in healthy volunteers by immunization with a vaccine candidate against typhoid fever. Immunol Lett 93: 115-122, 2004.

19. Hodak H and Galan JE: A Salmonella typhi homologue of bacteriophage muramidases controls typhoid toxin secretion. EMBO Rep 14: 95-102, 2013.

20. MacLennan CA, Martin LB and Micoli F: Vaccines against invasive Salmonella disease: Current status and future directions. Hum Vaccin Immunother 10: 1478-1493, 2014.

21. Tennant SM and Levine MM: Live attenuated vaccines for invasive Salmonella infections. Vaccine 33 (Suppl 3): C36-C41, 2015

22. Tennant SM, Wang JY, Galen JE, Simon R, Pasetti MF, Gat O and Levine MM: Engineering and preclinical evaluation of attenuated nontyphoidal Salmonella strains serving as live oral vaccines and as reagent strains. Infect Immun 79: 4175-4185, 2011.

23. Tacket CO, Sztein MB, Losonsky GA, Wasserman SS, Nataro JP, Edelman R, Pickard D, Dougan G, Chatfield SN and Levine MM: Safety of live oral Salmonella typhi vaccine strains with deletions in htrA and aroC aroD and immune response in humans. Infect Immun 65: 452-456, 1997

24. Angelakopoulos $\mathrm{H}$ and Hohmann EL: Pilot study of phoP/phoQ-deleted Salmonella enterica serovar typhimurium expressing Helicobacter pylori urease in adult volunteers. Infect Immun 68: 2135-2141, 2000.

25. Tran TH, Nguyen TD, Nguyen TT, Ninh TT, Tran NB, Nguyen VM, Tran TT, Cao TT, Pham VM, Nguyen TC, et al: A randomised trial evaluating the safety and immunogenicity of the novel single oral dose typhoid vaccine M01ZH09 in healthy Vietnamese children. PLoS One 5: e11778, 2010.

26. Lyon CE, Sadigh KS, Carmolli MP, Harro C, Sheldon E, Lindow JC, Larsson CJ, Martinez T, Feller A, Ventrone CH, et al: In a randomized, double-blinded, placebo-controlled trial, the single oral dose typhoid vaccine, M01ZH09, is safe and immunogenic at doses up to $1.7 \times 10(10)$ colony-forming units. Vaccine 28: 3602-3608, 2010.

27. Ault A, Tennant SM, Gorres JP, Eckhaus M, Sandler NG, Roque A, Livio S, Bao S, Foulds KE, Kao SF, et al: Safety and tolerability of a live oral Salmonella typhimurium vaccine candidate in SIV-infected nonhuman primates. Vaccine 31: 5879-5888, 2013

28. Eisenreich W, Dandekar T, Heesemann J and Goebel W: Carbon metabolism of intracellular bacterial pathogens and possible links to virulence. Nat Rev Microbiol 8: 401-412, 2010.

29. Abrahams GL and Hensel M: Manipulating cellular transport and immune responses: Dynamic interactions between intracellular Salmonella enterica and its host cells. Cell Microbiol 8: 728-737, 2006

30. Bowden SD, Rowley G, Hinton JC and Thompson A: Glucose and glycolysis are required for the successful infection of macrophages and mice by Salmonella enterica serovar typhimurium. Infect Immun 77: 3117-3126, 2009.

31. Klose KE and Mekalanos JJ: Simultaneous prevention of glutamine synthesis and high-affinity transport attenuates Salmonella typhimurium virulence. Infect Immun 65: 587-596, 1997.
32. Postma PW, Lengeler JW and Jacobson GR: Phosphoenolpy ruvate:Carbohydrate phosphotransferase systems of bacteria. Microbiol Rev 57: 543-594, 1993.

33. Deutscher J, Francke C and Postma PW: How phosphotransferase system-related protein phosphorylation regulates carbohydrate metabolism in bacteria. Microbiol Mol Biol Rev 70: 939-1031, 2006.

34. Zhi Y, Lin SM, Jang AY, Ahn KB, Ji HJ, Guo HC, Lim S and Seo HS: Effective mucosal live attenuated Salmonella vaccine by deleting phosphotransferase system component genes ptsI and crr. J Microbiol 57: 64-73, 2019.

35. Maze A, Glatter T and Bumann D: The central metabolism regulator EIIAGlc switches Salmonella from growth arrest to acute virulence through activation of virulence factor secretion. Cell Rep 7: 1426-1433, 2014

36. Luo Y, Kong Q, Yang J, Golden G, Wanda SY, Jensen RV, Ernst PB and Curtiss R III: Complete genome sequence of the universal killer Salmonella enterica serovar typhimurium UK-1 (ATCC 68169). J Bacteriol 193: 4035-4036, 2011.

37. Datsenko KA and Wanner BL: One-step inactivation of chromosomal genes in Escherichia coli K-12 using PCR products. Proc Natl Acad Sci USA 97: 6640-6645, 2000.

38. Ebel-Tsipis J, Fox MS and Botstein D: Generalized transduction by bacteriophage P22 in Salmonella typhimurium. II. Mechanism of integration of transducing DNA. J Mol Boil 71: 449-469, 1972.

39. Davis RW, Botstein D and Roth JR: Advanced Bacterial Genetics. Cold Spring Harbor Laboratory, Cold Spring Harbor, NY, 1980.

40. Miller JH: Experiments in molecular genetics. Cold Spring Harbor Laboratory, Cold Spring Harbor, NY, 1972.

41. Coombes BK, Coburn BA, Potter AA, Gomis S, Mirakhur K, Li Y and Finlay BB: Analysis of the contribution of Salmonella pathogenicity islands 1 and 2 to enteric disease progression using a novel bovine ileal loop model and a murine model of infectious enterocolitis. Infect Immun 73: 7161-7169, 2005.

42. Yu XJ, McGourty K, Liu M, Unsworth KE and Holden DW: $\mathrm{pH}$ sensing by intracellular Salmonella induces effector translocation. Science 328: 1040-1043, 2010.

43. Livak KJ and Schmittgen TD: Analysis of relative gene expression data using real-time quantitative PCR and the 2(-Delta Delta C(T)) method. Methods 25: 402-408, 2001.

44. Kim W and Surette MG: Swarming populations of Salmonella represent a unique physiological state coupled to multiple mechanisms of antibiotic resistance. Biol Proced Online 5: 189-196, 2003.

45. Nishikawa F, Kita E, Matsui N and Kashiba S: Transfer of protection to murine typhoid conferred by L-form Salmonella typhimurium in dependence of cooperation between $\mathrm{L}$ form-adopted macrophages and $\mathrm{L}$ form-induced Lyt $-2^{+} \mathrm{T}$ cells Microbiol Immunol 38: 201-207, 1994.

46. Meyerholz DK and Stabel TJ: Comparison of early ileal invasion by Salmonella enterica serovars choleraesuis and typhimurium. Vet Pathol 40: 371-375, 2003.

47. Haque A, Bowe F, Fitzhenry RJ, Frankel G, Thomson M, Heuschkel R, Murch S, Stevens MP, Wallis TS, Phillips AD and Dougan G: Early interactions of Salmonella enterica serovar typhimurium with human small intestinal epithelial explants. Gut 53: 1424-1430, 2004.

48. Tierrez A and Garcia-del Portillo F: New concepts in Salmonella virulence: The importance of reducing the intracellular growth rate in the host. Cell Microbiol 7: 901-909, 2005

49. Marcus SL, Brumell JH, Pfeifer CG and Finlay BB: Salmonella pathogenicity islands: Big virulence in small packages. Microbes Infect 2: 145-156, 2000

50. Hensel M: Salmonella pathogenicity island 2. Mol Microbiol 36: 1015-1023, 2000

51. Lostroh CP and Lee CA: The HilA box and sequences outside it determine the magnitude of HilA-dependent activation of $\mathrm{P}(\mathrm{prgH})$ from Salmonella pathogenicity island 1. J Bacteriol 183: 4876-4885, 2001.

52. Bustamante VH, Martinez LC, Santana FJ, Knodler LA, Steele-Mortimer $\mathrm{O}$ and Puente JL: HilD-mediated transcriptional cross-talk between SPI-1 and SPI-2. Proc Natl Acad Sci USA 105: 14591-14596, 2008.

53. Haselbeck AH, Panzner U, Im J, Baker S, Meyer CG and Marks F: Current perspectives on invasive nontyphoidal Salmonella disease. Curr Opin Infect Dis 30: 498-503, 2017.

54. Darji A, zur Lage S, Garbe AI, Chakraborty T and Weiss S: Oral delivery of DNA vaccines using attenuated Salmonella typhimurium as carrier. FEMS Immunol Med Microbiol 27: 341-349, 2000. 
55. Levine MM, Ferreccio C, Abrego P, Martin OS, Ortiz E and Cryz S: Duration of efficacy of Ty21a, attenuated Salmonella typhi live oral vaccine. Vaccine 17 (Suppl 2): S22-S27, 1999.

56. Hoiseth SK and Stocker BA: Aromatic-dependent Salmonella typhimurium are non-virulent and effective as live vaccines. Nature 291: 238-239, 1981.

57. Pasquali P, Ammendola S, Pistoia C, Petrucci P, Tarantino M, Valente C, Marenzoni ML, Rotilio G and Battistoni A: Attenuated Salmonella enterica serovar Typhimurium lacking the ZnuABC transporter confers immune-based protection against challenge infections in mice. Vaccine 26: 3421-3426, 2008.

58. Pesciaroli M, Aloisio F, Ammendola S, Pistoia C, Petrucci P, Tarantino M, Francia M, Battistoni A and Pasquali P: An attenuated Salmonella enterica serovar Typhimurium strain lacking the ZnuABC transporter induces protection in a mouse intestinal model of Salmonella infection. Vaccine 29: 1783-1790, 2011.

59. Gradassi M, Pesciaroli M, Martinelli N, Ruggeri J, Petrucci P, Hassan WH, Raffatellu M, Scaglione FE, Ammendola S, Battistoni A, et al: Attenuated Salmonella enterica serovar Typhimurium lacking the ZnuABC transporter: An efficacious orally-administered mucosal vaccine against salmonellosis in pigs. Vaccine 31: 3695-3701, 2013.

60. Pesciaroli M, Gradassi M, Martinelli N, Ruggeri J, Pistoia C, Raffatellu M, Magistrali CF, Battistoni A, Pasquali P and Alborali GL: Salmonella Typhimurium lacking the Znuabc transporter is attenuated and immunogenic in pigs. Vaccine 31: 2868-2873, 2013

61. Sittka A, Pfeiffer V, Tedin K and Vogel J: The RNA chaperone Hfq is essential for the virulence of Salmonella typhimurium. Mol Microbiol 63: 193-217, 2007.

62. Lopez-Garrido J and Casadesus J: Regulation of Salmonella enterica pathogenicity island 1 by DNA adenine methylation. Genetics 184: 637-649, 2010.

63. Hindle Z, Chatfield SN, Phillimore J, Bentley M, Johnson J, Cosgrove CA, Ghaem-Maghami M, Sexton A, Khan M, Brennan FR, et al: Characterization of Salmonella enterica derivatives harboring defined aroC and Salmonella pathogenicity island 2 type III secretion system (ssaV) mutations by immunization of healthy volunteers. Infect Immun 70: 3457-3467, 2002.

64. Hansen-Wester I and Hensel M: Salmonella pathogenicity islands encoding type III secretion systems. Microbes Infect 3: 549-559, 2001.

65. Le Bouguenec $\mathrm{C}$ and Schouler C: Sugar metabolism, an additional virulence factor in enterobacteria. Int J Med Microbiol 301: 1-6, 2011.
66. Wilharm G and Heider C: Interrelationship between type three secretion system and metabolism in pathogenic bacteria. Front Cell Infect Microbiol 4: 150, 2014.

67. Teplitski M, Goodier RI and Ahmer BM: Catabolite repression of the SirA regulatory cascade in Salmonella enterica. Int J Med Microbiol 296: 449-466, 2006.

68. Martinez LC, Yakhnin H, Camacho MI, Georgellis D, Babitzke P, Puente JL and Bustamante VH: Integration of a complex regulatory cascade involving the SirA/BarA and Csr global regulatory systems that controls expression of the Salmonella SPI-1 and SPI-2 virulence regulons through HilD. Mol Microbiol 80: 1637-1656, 2011.

69. Poncet S, Milohanic E, Maze A, Abdallah JN, Aké F, Larribe M, Deghmane AE, Taha MK, Dozot M, De Bolle X, et al: Correlations between carbon metabolism and virulence in bacteria. Contrib Microbiol 16: 88-102, 2009.

70. Stecher B, Hapfelmeier S, Muller C, Kremer M, Stallmach T and Hardt WD: Flagella and chemotaxis are required for efficient induction of Salmonella enterica serovar Typhimurium colitis in streptomycin-pretreated mice. Infect Immun 72: 4138-4150, 2004.

71. Stecher B, Barthel M, Schlumberger MC, Haberli L, Rabsch W, Kremer M and Hardt WD: Motility allows $S$. Typhimurium to benefit from the mucosal defence. Cell Microbiol 10: 1166-1180, 2008.

72. Lim S, Han A, Kim D and Seo HS: Transcriptional profiling of an attenuated Salmonella Typhimurium ptsI mutant strain under low-oxygen conditions using microarray analysis. J Bacteriol Virol 45: 1-15, 2015

73. Lim S, Kim M, Choi J and Ryu S: A mutation in tdcA attenuates the virulence of Salmonella enterica serovar Typhimurium. Mol Cells 29: 509-517, 2010.

74. Baba T, Ara T, Hasegawa M, Takai Y, Okumura Y, Baba M, Datsenko KA, Tomita M, Wanner BL and Mori H: Construction of Escherichia coli K-12 in-frame, single-gene knockout mutants: The Keio collection. Mol Syst Biol 2: 2006 0008, 2006.

This work is licensed under a Creative Commons Attribution-NonCommercial-NoDerivatives 4.0 International (CC BY-NC-ND 4.0) License. 